\title{
Measuring the perceived quality of ophthalmology services in private organizations. A marketing perspective
}

\author{
Gheorghe Iuliana Raluca, Gheorghe Consuela-Mădălina, Purcărea Victor Lorin \\ “Carol Davila” University of Medicine and Pharmacy, Bucharest, Romania \\ Correspondence to: Gheorghe IR, PhD, \\ "Carol Davila" University of Medicine and Pharmacy, Bucharest, Romania, \\ 8 Eroii Sanitari Bld., District 5, Bucharest, Romania, \\ E-mail: raluca.gheorghe@umfcd.ro
}

Accepted: January 14th, 2018

\begin{abstract}
Nowadays, the competition registered on the Romanian markets regarding the activity of private ophthalmology organizations has raised their interest in developing consumeroriented strategies. The key factor that assures a differentiation as well as a competitive advantage is the service quality from a marketing perspective.

Objectives: From a marketing perspective, service quality is measured as a perceived discrepancy between the consumers' expectations and was actually performed in health care services. The most widely and validated measurement is the SERVQUAL scale. However, a variety of SERVQUAL scales have been applied in different health care environments without taking into consideration the specialty of the health care service. Thus, the objective of this paper was to measure the service quality in the Romanian ophthalmology private organizations using the SERVQUAL measurement, by identifying the SERVQUAL dimensions, which register the highest and the lowest gap scores.

Materials and methods: The instrument for data collection was the SERVQUAL selfadministered questionnaire that consisted of 22 items measured on a 5-point Likert scale. The sample size encompassed 100 participants and the sampling technique was the snowball. The internal consistency, validity and the reliability of the SERVQUAL scale was determined by the Cronbach's alpha coefficients and factor analysis. The SERVQUAL questionnaire focused on 5 dimensions (tangibles, reliability, assurance, empathy and responsiveness) and each dimension, in its turn, was characterized by different items.

Results: The mean age of the participants was 49.52 years, with a mean income of 3031 Romanian Currency and the mean period of wearing eyeglasses was 5 years $( \pm 2)$. Further, there were $47 \%$ females and $53 \%$ males. The overall internal consistency of the SERVQUAL scale, as well as the dimensions' internal consistency were all above 0.7 and the factor analysis revealed that the items loaded properly on each dimension. Moreover, the gap scores of the SERVQUAL scale's dimensions pinpointed that the highest gap score was registered by the Tangibles dimension and the lowest gap score was registered by the Reliability dimension.

Conclusions: Performing the ophthalmology service right the first time, contributes significantly to the improvement of the marketing effectiveness and the operating efficiency.

Keywords: ophthalmology services, service quality, SERVQUAL scale
\end{abstract}




\section{Introduction}

Nowadays, the competition in private health care ophthalmology organizations has increased and, in order to survive, they have to deliver services that satisfy the consumer's needs $[\mathbf{1 , 2}]$. The key factor in differentiating services, which also assures a competitive advantage as well as consumer retention, positive word-of-mouth, increased profitability, financial performance and consumer satisfaction, is the service quality [3-5].

Studies in the health care field confirmed that high quality services are linked directly to increased market share, profits, and savings for an organization [6]. More exactly, since the 90s, the patients' quality perceptions have accounted for $17-27 \%$ of the variation in a health care organization's net revenue and asset returns [7].

By nature, healthcare is a credence service, patients being unable to assess the technical service quality accurately, therefore, functional quality is the primary judgmental feature. Thus, quality is a judgmental concept [12] and patients form their perceptions on the operational part of the quality [13].

In ophthalmology, service quality takes the same shape and has similar meaning to what was aforementioned about health services, in general, but it may register some differences related to the measurement scale.

During the 1980s, the service quality research increased and led to different empirical methods because service quality is almost impossible to measure [14]. However, the marketing experts determined the service quality based on the consumer perceptions. The most widely and validated scale in scientific literature is the SERVQUAL scale. Despite being a reliable instrument, many specialists consider it inappropriate, if used in health care services.

Therefore, the objective of this paper was to measure the service quality in the Romanian ophthalmology private organizations using the SERVQUAL instrument. More specifically, we wanted to assess whether the SERVQUAL scale could be successfully applied in private ophthalmology services in Romania and determine the dimensions that register the highest gap scores.

\section{Literature review}

From a marketing perspective, perceived service quality is a concept that measures the discrepancy between the consumers' expectations and their perceptions related to a health care service [8]. As such, expectations are reflected in the desires of the consumers that they believe a health care organization should provide. Once formed, expectations become important for consumers as they will help them make comparisons between what they anticipated and what they actually received [9]. On the other hand, perceptions refer to the consumer's evaluation of the health care service provider, being considered, in fact, a combination between what is delivered and how it is delivered $[\mathbf{9 , 1 0}]$.

Still, like quality in most services, health quality is difficult to measure owing to the characteristics of services, namely intangibility, heterogeneity, and inseparability. Moreover, health quality perceptions rise according to the service size, complexity, specialization, and expertise within the health care organizations [11].

\subsection{Measures of service quality}

Considering the importance of service quality in health services, there is no surprise that many experts still spend a lot of their time understanding the underlying dimensions of the concept [8].

Many researchers concluded that from a consumer's perspective service quality should be defined by two dimensions [15-17]. For example, Lehtinen and Lehtinen [15] determined the service quality in terms of corporate quality, interactive quality and physical quality whereas Gronroos [16] revealed the components of service quality as technical quality and functional quality, meaning what is delivered and how the service is delivered, respectively. In the same vein as Gronroos' model approach [16], Berry [17] observed that service quality should encompass outcome quality and process quality.

Following the research of other marketing specialists, Parasuraman et al. [18] elaborated the most widely used, validated and generally accepted service quality measurement in the services literature, the SERVQUAL scale [19]. The SERVQUAL measure is a multi-item instrument that consists of 5 dimensions, 
determined in their turn, by 22 paired items [18]. In fact, the SERVQUAL scale measures the expectation-perception gap of consumers [20]. Moreover, the gap score is the outcome of the difference between perception and expectation scores. Thus, a positive gap score suggests that the expectations of consumers have been exceeded whereas a negative gap score indicates failure. Further, gap scores are usually analyzed as aggregated scores giving an overview of each dimension and emphasize the strengths and weaknesses embedded in the actual service quality performance.

The five dimensions that define the SERVQUAL instrument are the following [18]:

- The Tangibles dimension that focuses on the physical facilities, the equipment used and the appearance of the personnel;

- The Reliability dimension suggests the ability of the service provider to perform the delivery of the service as accurately as promised;

- The Responsiveness dimension indicates an organization's employees' willingness to provide the consumers a prompt service;

- The Assurance dimension concentrates on an organization's employees' knowledge and courtesy as well as their ability to inspire trust and confidence to consumers;

- The Empathy dimension consists of the ability of the organization's employees to provide caring and personalized attention to consumers.

Despite the fact that SERVQUAL has been widely spread and has been considered a reliable instrument, many specialists criticized it both methodologically and conceptually. The most important criticism brought to light was that the five dimensions cannot be universally applied in all service industries and should be carefully implemented on each service market [21]. Moreover, the five dimensions should be restrained to two dimensions, namely the core services and augmented services [22] or to technical and functional dimensions [16].

\subsection{Health Service Quality}

As mentioned before, service quality remains a critical issue in most service industries and even more in health care services. Today, patient's expectations changed as they became more informed and involved in the delivery of the service. As such, ensuring service quality is beneficial not only for the patients but also for the health care organizations. Investigating patients' expectations would provide useful information for the health care provider who wishes to control and improve his service performance.

In the health care sector, the traditional method to assess service quality is Donabedian's structure-process-outcome model that includes the following dimensions [23]:

- Structure- includes the setting of the health care organizations;

- Process- suggests how health care is technically delivered;

- Outcome emphasizes the result of medical care on the health and welfare of the patient.

Donabedian's model described quality as being more technical in nature rather than functional. In other words, it is not that commonly employed, as patients do not have the necessary medical knowledge to evaluate whether the health care service has been delivered properly. Moreover, there have been several attempts to assess the quality of a health care service based on two dimensions, but without any real success. For instance, even if technical quality has the highest priority, researchers resorted to measure it by proxy, helping patients make a difference between "curing" and "caring" services [24].

Despite all controversies related to the validity and reliability of the SERVQUAL scale, it proved to be efficiently applied in health care as well. Therefore, there have been shortened or extended versions of SERVQUAL with application in health care services in the scientific literature. For instance, Lim and Tang [25] extended the scale with 2 more dimensions, namely accessibility and affordability, Tucker and Adams [26] added caring and outcome while Johnston [27] shortened the initial SERVQUAL measurement, regrouping the items of the scale. Similarly, Tomes and Ng [28] integrated in the empathy dimension items that reflected understanding of the illness, relationship and mutual respect, dignity, physical environment and religious needs.

According to a research conducted by Purcărea et al. [29], who used the 22-item scale in measuring the health care service quality, it was concluded that the SERVQUAL scale might 
be successfully applied in this field as well. The mixed outcomes resulted from previous studies made us posited that the health service quality is far from being solved, more crucially if we were to take into consideration each medical specialty, such as ophthalmology.

\section{Materials and methods}

After the elaboration of the SERVQUAL scale, many specialists applied it on health care services in the shape of 22-item format or modified, proving its usefulness in assessing the service quality as perceived by consumers in hospitals, clinics and other medical centers $[30,31]$. Further, most studies used the SERVQUAL self-administered questionnaire, selecting the sample participants from the lists with patients of the health care organizations, regardless of the medical specialty and their geographic location. In this research, we selected our sample respondents using the snowball technique but taking into consideration the following criteria:

- The respondents' ages should have been more than 18 years;

- The respondents should have been wearing eyeglasses for more than 2 years;

- The respondents' last consultation should have taken place in a private ophthalmology organization from Bucharest.

The sample size was determined by using G*Power software and we concluded that a number of 150 participants should be enough to give us a clear overview of our researched objectives. From 150 participants, we validated 100 questionnaires, as many were not completely filled in or the respondents did not pay attention when filling in the questionnaire.

The instrument for data collecting was the SERVQUAL self-administered questionnaire, consisting of two sections, as it follows:

- The first section collected information about the demographic profile of the respondents such as age, gender, marital status, income, reason for visiting an ophthalmology organization and the period of wearing eyeglasses.

- The second section encompassed the 22paired questions that measured both expectations and perceptions on a 5-point Likert scale ranging from strongly agree (5) to strongly disagree (1).
The internal consistency, validity, and reliability of the SERVQUAL measurement was assessed by using the Cronbach's alpha coefficient and the factor analysis was performed in SPSS version 20.

In order to determine the SERVQUAL scale's consistency and reliability, the threshold for the Cronbach's alpha value was 0.7 , which is the accepted limit [32], whereas for the factor analysis, we eliminated values of items lower than 0.4 , which did not load properly on any latent factor, in our case being the SERVQUAL scale dimensions. Before performing the factor analysis, a preliminary statistical test was employed, namely the Kaiser-Meyer-Olkin (KMO) index accompanied by the Bartlett's test of sphericity in order to examine the intercorrelated items. Moreover, the KMO test has to have values greater than 0.5 and the Bartlett's test has to have a significant statistical level lower than 0.05. Consequently, the method used to uncover the latent variables, or in our case, the SERVQUAL scale's dimensions, was the correlation matrix, with the Varimax rotation.

\section{Findings}

\subsection{Demographic profile of the respondents}

The mean age of the participants was 49.52 years $( \pm 19.84)$, their mean income was 3031,00 $( \pm 1088)$ Romanian Currency and their mean period of wearing eyeglasses was 5 years $( \pm 2)$ (Table 1). Moreover, from 100 participants, $47 \%$ were females whereas 53\% were males and went for a consultation to an ophthalmologist due to a routine check-up (22\%), surgery (42\%) and even asking for second opinions (36\%) (Table 2).

Table 1. The mean age, income and the period of wearing eyeglasses of the respondents

$\begin{array}{rrr}\begin{array}{c}\text { Age of the } \\ \text { respondent }\end{array} & \begin{array}{c}\text { Income of } \\ \text { the } \\ \text { respondent }\end{array} & \begin{array}{c}\text { Period of } \\ \text { wearing } \\ \text { eyeglasses }\end{array} \\ 49,52 & 3031,61 & 5,00 \\ 19,847 & 1088,277 & 2,005\end{array}$

$\begin{array}{lrrr}\text { Mean } & 49,52 & 3031,61 & 5,00 \\ \text { Std. } & 19,847 & 1088,277 & 2,005 \\ \text { Deviation } & & & \\ \text { Minimum } & 18 & 711 & 2 \\ \text { Maximum } & 85 & 4922 & 8\end{array}$


Table 2. The distribution of the respondents' genders according to the marital status and the reasons for seeing an ophthalmologist

\begin{tabular}{|c|c|c|}
\hline Gender & Female & Male \\
\hline $\begin{array}{l}\text { Demographic } \\
\text { variable }\end{array}$ & Frequency & Frequency \\
\hline \multicolumn{3}{|l|}{ Marital status } \\
\hline Not married & $53.2 \%$ & $45.3 \%$ \\
\hline Married & $29.8 \%$ & $26.4 \%$ \\
\hline Separated & $17.0 \%$ & $28.3 \%$ \\
\hline \multicolumn{3}{|c|}{ Reasons for seeing an ophthalmologist } \\
\hline Routine check-up & $25.5 \%$ & $18.9 \%$ \\
\hline Surgery & $36.2 \%$ & $47.2 \%$ \\
\hline Second opinion & $38.3 \%$ & $34 \%$ \\
\hline
\end{tabular}

\subsection{The SERVQUAL scale applied in private ophthalmology services}

\subsubsection{Internal consistency of the SERVQUAL scale}

The overall internal consistency of the SERVQUAL scale, as well as the dimensions' internal consistency, was determined by the Cronbach's alpha coefficients as illustrated in table 3. As it can be observed, none of the scales had a Cronbach's alpha coefficient lower than 0.7 .

Table 4. The Rotated Matrix of the Expectation Scale

\begin{tabular}{|c|c|c|c|c|c|}
\hline & $\begin{array}{l}\text { Reliability } \\
\text { Dimension }\end{array}$ & $\begin{array}{l}\text { Empathy } \\
\text { Dimension }\end{array}$ & $\begin{array}{l}\text { Assurance } \\
\text { Dimension }\end{array}$ & $\begin{array}{l}\text { Responsiveness } \\
\text { Dimension }\end{array}$ & $\begin{array}{c}\text { Tangibles } \\
\text { Dimension }\end{array}$ \\
\hline e_ta1 & & & & & 0,843 \\
\hline e_ta2 & & & & & 0,807 \\
\hline e_ta3 & & & & & 0,872 \\
\hline e_ta4 & & & & & 0,829 \\
\hline e_rel1 & 0,844 & & & & \\
\hline e_rel2 & 0,854 & & & & \\
\hline e_rel3 & 0,829 & & & & \\
\hline e_rel4 & 0,829 & & & & \\
\hline e_rel5 & 0,850 & & & & \\
\hline e_resp1 & & & & 0,813 & \\
\hline e_resp2 & & & & 0,822 & \\
\hline e_resp3 & & & & 0,846 & \\
\hline e_resp4 & & & & 0,867 & \\
\hline e_ass1 & & & 0,879 & & \\
\hline
\end{tabular}

Table 3. Cronbach's alpha coefficients of the overall SERVQUAL scale, the expectation, and the perception scales as well as of every dimension included

\begin{tabular}{|c|c|c|c|}
\hline Dimensions & $\begin{array}{l}\text { No of } \\
\text { item } \\
s\end{array}$ & $\begin{array}{l}\text { Expectatio } \\
\text { n }\end{array}$ & $\begin{array}{l}\text { Perceptio } \\
\text { n }\end{array}$ \\
\hline Tangibles & 4 & 0,86 & 0,87 \\
\hline Reliability & 5 & 0,90 & 0,89 \\
\hline $\begin{array}{l}\text { Responsivenes } \\
\text { s }\end{array}$ & 4 & 0,86 & 0,87 \\
\hline Assurance & 4 & 0,89 & 0,87 \\
\hline \multirow[t]{3}{*}{ Empathy } & 5 & 0,86 & 0,89 \\
\hline & & 0,78 & 0,73 \\
\hline & & \multicolumn{2}{|c|}{ SERVQUAL scale: 0,82} \\
\hline
\end{tabular}

\subsubsection{Factor analysis}

According to the KMO index and the Bartlett's test of sphericity, both the expectation scale and the perception scale had values higher than 0.80 with a significant level higher than 0.05., suggesting that the items included in the questionnaire were inter-correlated and the factor analysis was suitable to be performed. As such, the factor analysis for the expectation scale and the perception scale revealed that every item of the questionnaire loaded accordingly on each dimension (table 4 and table 5). The dimensions of the expectation scale showed a $72.20 \%$ explanation of the variance whereas the dimensions in the perception scale explained $72.85 \%$ of the variance.

\section{Component}



e_ass2
e_ass3
e_ass4
e_emp1
0,818
e_emp2
0,859
e_emp3
0,844
e_emp4
0,790
e_emp5
0,723

0,830

0,851

0,858

Table 5. The Rotated Matrix of the Perception Scale

\section{Component}

\begin{tabular}{|c|c|c|c|c|c|}
\hline & $\begin{array}{l}\text { Empathy } \\
\text { Dimension }\end{array}$ & $\begin{array}{l}\text { Reliability } \\
\text { Dimension }\end{array}$ & $\begin{array}{l}\text { Assurance } \\
\text { Dimension }\end{array}$ & $\begin{array}{l}\text { Tangibles } \\
\text { Dimension }\end{array}$ & $\begin{array}{c}\text { Responsiveness } \\
\text { Dimension }\end{array}$ \\
\hline p_ta1 & & & & 0,842 & \\
\hline p_ta2 & & & & 0,869 & \\
\hline p_ta3 & & & & 0,808 & \\
\hline p_ta4 & & & & 0,854 & \\
\hline p_rel1 & & 0,853 & & & \\
\hline p_rel2 & & 0,828 & & & \\
\hline p_rel3 & & 0,805 & & & \\
\hline p_rel4 & & 0,810 & & & \\
\hline p_rel5 & & 0,848 & & & \\
\hline p_resp1 & & & & & 0,853 \\
\hline p_resp2 & & & & & 0,857 \\
\hline p_resp3 & & & & & 0,841 \\
\hline p_resp4 & & & & & 0,822 \\
\hline p_ass1 & & & 0,862 & & \\
\hline p_ass2 & & & 0,859 & & \\
\hline p_ass3 & & & 0,844 & & \\
\hline p_ass4 & & & 0,821 & & \\
\hline p_emp1 & 0,807 & & & & \\
\hline p_emp2 & 0,862 & & & & \\
\hline p_emp3 & 0,849 & & & & \\
\hline p_emp4 & 0,851 & & & & \\
\hline p_emp5 & 0,848 & & & & \\
\hline
\end{tabular}

\subsubsection{The Gap analysis}

As mentioned earlier, the service quality is measured as the difference between the perception and the expectation of each dimension, namely the "gap" analysis. Tables 610 indicate the gaps assessed for every dimension included in the SERVQUAL scale. 
Table 6. The Tangibles Dimension Gap Score

$\begin{array}{llll}\begin{array}{l}\text { Items included in the } \\ \text { Tangibles Dimension }\end{array} & \text { Expectation Scale } & \text { Perception Scale } & \begin{array}{l}\text { Gap Score (Expectation- } \\ \text { Perception) }\end{array} \\ \text { IT1 } & 3,06 & 3,09 & -0,03 \\ \text { IT2 } & 3,08 & 2,95 & 0,13 \\ \text { IT3 } & 3,18 & 2,97 & 0,21 \\ \text { IT4 } & 3,09 & 0,04 \\ & 3,13 & 0.35\end{array}$

Table 7. The Reliability Dimension Gap Score

$\begin{array}{llll}\begin{array}{l}\text { Items included in the } \\ \text { Reliability Dimension }\end{array} & \text { Expectation Scale } & \text { Perception Scale } & \begin{array}{l}\text { Gap Score (Expectation- } \\ \text { Perception) }\end{array} \\ \text { IT1 } & 3,05 & 3 & 0,05 \\ \text { IT2 } & 3 & 3,07 & -0,07 \\ \text { IT3 } & 2,99 & 3,03 & -0,04 \\ \text { IT4 } & 2,97 & 2,98 & -0,01 \\ \text { IT5 } & 3,07 & 3,08 & -0,01 \\ & \text { Reliability Dimension Gap Score: } & -0,08\end{array}$

Table 8. The Responsiveness Dimension Gap Score

$\begin{array}{llll}\begin{array}{l}\text { Items included in the } \\ \text { Responsiveness Dimension }\end{array} & \text { Expectation Scale } & \text { Perception Scale } & \begin{array}{l}\text { Gap Score } \\ \text { (Expectation- } \\ \text { Perception) }\end{array} \\ \text { IT1 } & 2,83 & 2,87 & -0,04 \\ \text { IT2 } & 2,94 & 2,82 & 0,12 \\ \text { IT3 } & 2,93 & 2,90 & 0,03 \\ \text { IT4 } & 3,02 & 2,96 & 0,06 \\ & \text { Responsiveness Dimension Gap Score: } & 0,17\end{array}$

Table 9. The Assurance Dimension Gap Score

$\begin{array}{llll}\begin{array}{l}\text { Items included in the } \\ \text { Assurance Dimension }\end{array} & \text { Expectation Scale } & \text { Perception Scale } & \begin{array}{l}\text { Gap Score (Expectation- } \\ \text { Perception) }\end{array} \\ \text { IT1 } & 3,07 & 3,05 & 0,02 \\ \text { IT2 } & 2,90 & 3,05 & 0,25 \\ \text { IT3 } & 2,96 & 3,07 & -0,11 \\ \text { IT4 } & 3,06 & -0,08 \\ & \text { Assurance Dimension Gap Score: } & 0,08\end{array}$

Table 10. The Empathy Dimension Gap Score

$\begin{array}{llll}\begin{array}{l}\text { Items included in the } \\ \text { Empathy Dimension }\end{array} & \text { Expectation Scale } & \text { Perception Scale } & \begin{array}{l}\text { Gap Score (Expectation- } \\ \text { Perception) }\end{array} \\ \text { IT1 } & 3,07 & 3,12 & 0,04 \\ \text { IT2 } & 3,08 & 3,01 & 0,07 \\ \text { IT3 } & 2,91 & 2,87 & 0,04 \\ \text { IT4 } & 3,12 & -0,09 \\ \text { IT5 } & 2,03 & 0,05 \\ & 3,04 & 0,11\end{array}$

\section{Discussion}

The investigation of the quality in health care services has raised many controversies regarding their implementation and validation owing to their credence particularities. Based on different studies, the SERVQUAL scale has been the most widely used and employed in a vast array of fields. As such, the SERVQUAL scale is materialized in a gap measured between the expectations and perceptions of a consumer related to a health care service.

From a marketing perspective, understanding the health care consumer in a 
competitive market, is highly essential as it may bring new insights in the health care industry overall. For instance, an improvement in the health care delivery of services can reduce the in-patient stays and lower mortality as well as deliver value to consumers. Therefore, identifying the dimensions' gap scores may turn out to be useful from a strategic perspective, as they will indicate which components should be used as a competitive advantage.

The SERVQUAL scale has been frequently applied in health care services without keeping in mind the specialty of the medical service but the type of health care organization. For example, Mangold and Babakus [31] measured the service quality in a US hospital, concluding that the assurance dimension has the lowest gap score whereas the empathy dimension has the highest gap score. Further, according to Lam [30], who applied the SERVQUAL scale in a hospital in Hong Kong, the highest gap score was registered by the empathy dimension and in a hospital located in Singapore, the dimension with the highest gap score was responsiveness [25]. In Romania, Popa et al. [33] determined the quality of health care services using the SERVQUAL scale in a hospital in Oradea and indicated that the empathy dimension registered the highest gap score whereas Purcarea et al. [29] confirmed that the tangibles dimension should be considered a competitive advantage.

As mentioned earlier, none of the above studies took into consideration the specialty of the health care service. The objective of this paper was to measure the service quality in the Romanian ophthalmology private organizations using the SERVQUAL scale. More specifically, we wanted to identify whether the SERVQUAL scale could be successfully applied in ophthalmology services in Romania and determine the dimensions that register the highest gap scores. Thus, the highest gap score was registered by the Tangibles Dimension and the lowest gap score was registered by the Reliability Dimension (Fig. 1).

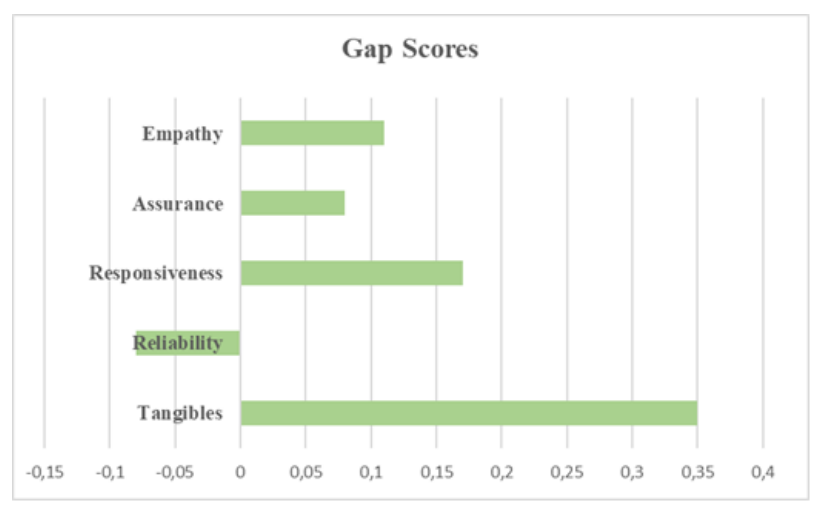

Fig. 1 The SERVQUAL Scale's Gap Score Dimensions

According to some specialists, assuring reliability is paramount for every service industry and, in addition, is the essence of the service quality, which, in turn, is the core pillar for services marketing excellence [34]. Consequently, performing the ophthalmology service right the first time contributes significantly to the improvement of marketing effectiveness and the operating efficiency as well as to achieving higher current-consumer retention rates, increased word of mouth communication, and reduction in the need to reperform the service (Fig. 2). 


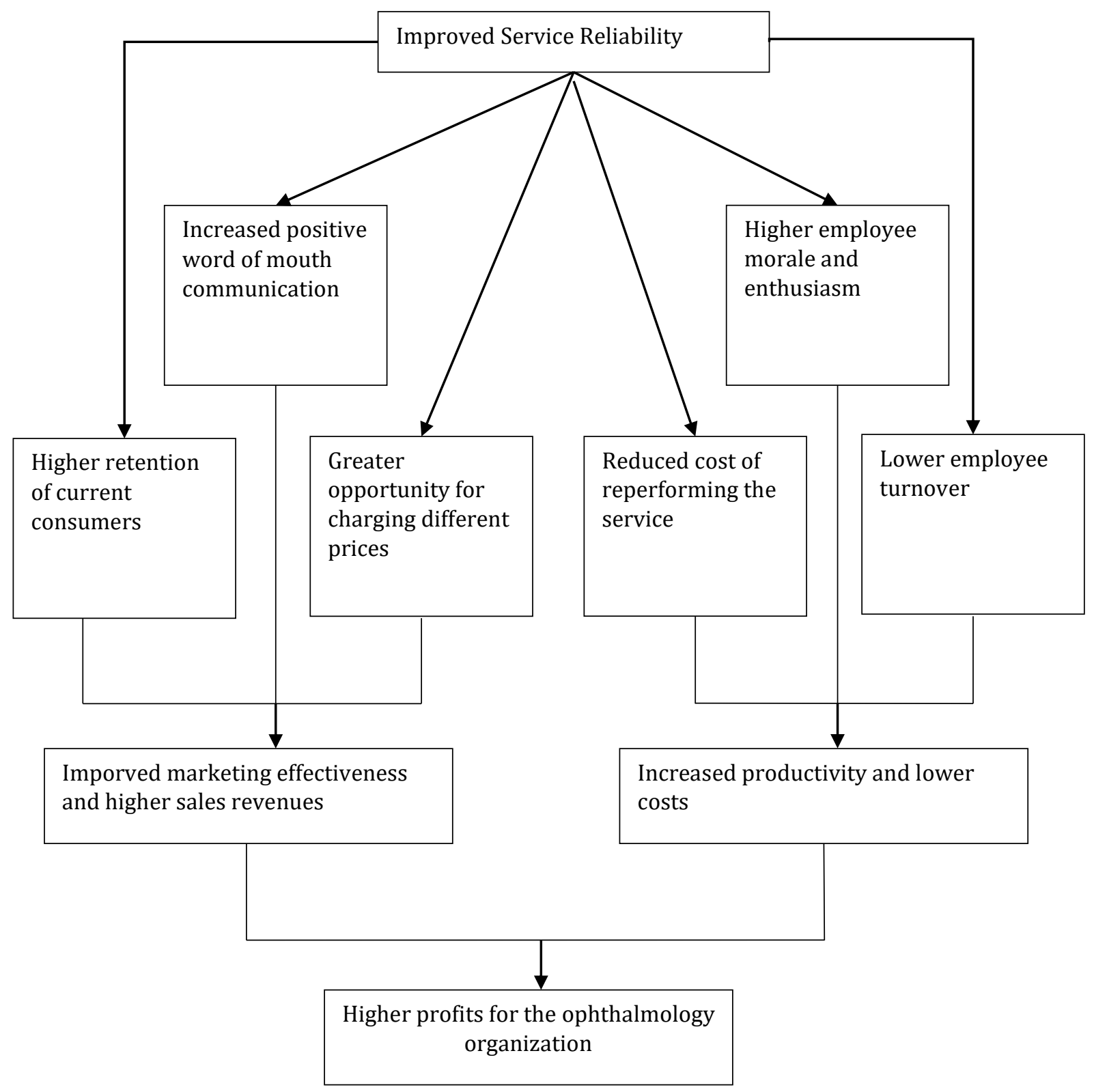

Fig. 2 The benefits of performing a reliable ophthalmology service from a marketing perspective [35, p. 18]

\section{References}

1. Cronin JJ, Taylor SA. Measuring service quality: a reexamination and extension. Journal of Marketing. 1992; 56(3): 55-68.

2. Parasuraman A, Berry L, Zeithaml V. Refinement and reassessment of the SERVQUAL scale. Journal of Retailing. 1991; 66(2): 34-45.

3. Cronin JJ, Brady MK, Hult GTM. Assessing the effects of quality, value, and customer satisfaction on consumer behavioral intentions in service environments. Journal of Retailing. 2000; 76(2): 193-218.

4. Gounaris SP, Stathakopoulos V, Athanassopoulos AD. Antecedents to perceived service quality: an exploratory study in the banking industry. The International Journal of Bank Marketing. 2003; 21(4/5): 168-190.

5. Yoon S, Suh H. Ensuring IT consulting SERVQUAL and user satisfaction: a modified measurement tool. Information Systems Frontiers. 2004; 6(4): 341-351.

6. Devlin SJ, Dong HK. Service quality from the customers' perspective. Marketing Research. 1994; 6(1 (Winter)): 5-13. 
7. Nelson EC, Rust RT, Zahorik A, Rose RL, Batalden P, Siemanski BA. Do patient perceptions of quality relate to hospital financial performance?. Journal of Health Care Marketing. 1992; 12(4): 6-13.

8. Parasuraman A, Zeithaml VA, Berry LL. A conceptual model of service quality and its implications for future research. Journal of Marketing. 1985; 49: 41-50.

9. Lovelock C, Wright L. Principles of service marketing and management. 2002, New Jersey, Prentice Hall.

10. Zeithaml V, Berry L, Parasuraman A. The nature and determinants of customer expectations of service. Journal of the Academy of Marketing Science. 1993; 21(1): 1-12.

11. Eiriz V, Figueiredo JA. Quality evaluation in health care services based Customer provider relationships. International Journal of Health Care. 2005; 18(6):40412.

12. Turner P, Pol L. Beyond patient satisfaction. Journal of Health Care Marketing. 1995; 15 (3): 45-53.

13. Taylor SA Cronin JJ. Modeling patient satisfaction and service quality. Journal of Health Care Marketing. 1994; 14(1): 34-44.

14. Harvey J. Service quality: a tutorial. Journal of Operations Management. 1998; 16: 583-597.

15. Lehtinen U, Lehtinen J. Service Quality: a study of quality dimensions. Service Management Institute, Helsinki, 1982.

16. Gronroos C. Strategic Management and Marketing in the Service Sector. Boston: Marketing Science Institute, 1983.

17. Berry L. Services Marketing is different. Business. 1983; 30: 23-26.

18. Parasuraman A, Zeithaml V, Berry L. SERVQUAL: a multiple-item scale for measuring consumer perceptions of service quality. Journal of Retailing. 1988; 64(1):12-40.

19. Ladhari R. A review of twenty years of SERVQUAL research. International Journal of Quality and Service Sciences. 2009; 1: 172-198.

20. Babakus E, Mangold W.G. Adapting the SERVQUAL scale to hospital services: An empirical investigation. Health Services Research. 1992; 26: 768-786.

21. Carman JM. Consumer perceptions of service quality: an assessment of the SERVQUAL dimensions. Journal of Retailing. 1990; 66(1): 33-55.

22. McDougall G, Levesque T. A revised review of service quality dimension: an empirical investigation. Journal of Professional Service Marketing. 1994; 11(1): 189210.

23. Donabedian A. Criteria and standards for quality assessment and monitoring. Quality Research Bulletin. 1986; 12 (3): 99-108.

24. Gabbott M, Hogg G. Consumers and Services. 1998, Chichester, Wiley.

25. Lim PC, Tang NKH. A study of patients' expectations and satisfaction in Singapore hospitals. International Journal of Health Care Quality Assurance. 2000; 13: 290-299.

26. Tucker JL Adams SR. Incorporating patients' assessments of satisfaction and quality: an integrative model of patients' evaluations of their care. Managing Service Quality. 2001; 11(4): 272-287.
27. Johnston R. The determinants of service quality: satisfiers and dissatisfiers. International Journal of Service Industry Management. 1995; 6(5): 53-71.

28. Tomes A, Ng SCP. Service quality in hospital care: the development of in-patient questionnaire. International of Health Care Quality Assurance. 1995; 8(3): 25-33.

29. Purcărea VL, Gheorghe IR, Petrescu CM. The assessment of perceived service quality of public health care services in Romania using the SERVQUAL scale. Procedia Economics and Finance. 2013; 6: 573585.

30. Lam SSK. Servqual: A tool for measuring patients' opinions of hospital service quality in Hong Kong. Total Quality Management. 1997; 8(4): 145-152.

31. Mangold WG, Babakus E. Service quality: The frontstage vs. the back-stage perspective. Journal of Services Marketing. 1991; 5(4): 59-70.

32. Nunnally JC. Psychometric Theory, 1978, New York, McGraw-Hill.

33. Popa AL, Rosca RD, Mihoc F. Investigating the Patient satisfaction within Romanian Public and Private Hospitals. 2011. http://core.kmi.open.ac.uk/display/1057879.

34. Berry LL, Parasuraman A, Zeithaml V. Improving service quality in America: lessons learned. Academy of Management Executive. 1994; 8(2):32-52.

35. Berry LL, Parasuraman A. Marketing Services. Competing through quality, 1991, The Free Press. 